\title{
Estimation of the wind turbulence intensity under different classes of atmospheric stability on the Benin coast in Cotonou by a new model
}

\author{
H. E. V. Donnou ${ }^{1}$, A. B. Akpo' ${ }^{1}$, G. H. Hounguè ${ }^{1}$, B. B. Kounouhewa ${ }^{1}$ \\ ${ }^{1}$ Laboratoire de Physique du Rayonnement (LPR), Faculté des Sciences et Techniques (FAST), \\ Université d'Abomey-Calavi, 01 BP 526, Cotonou, Benin. \\ Corresponding author: donhelv@yahoo.fr
}

\section{INFOS SUR L'A R T I C L E}

Historique de l'article:

Reçu le : 31 juillet 2019

Reçu en format revisé le : 09 novembre 2019

Accepté le : 13 novembre 2019

Mots-Clés: model,wind, turbulence, atmosphere, stability

\begin{abstract}
A B S T R A C T
A new model for estimating the wind turbulence intensity under different atmospheric stability classes has been proposed in this study. The data used were recorded at $10 \mathrm{~m}$ above the ground on a time scale of $10 \mathrm{~min}$ at the Cotonou Port site. From the Cheung model combined with the expression of the average wind shear profile proposed by Panofsky, we modified the first term of the model in multiplying it by the wind speed. The adjustment parameters of this new model thus obtained are determined by numerical simulation based on the Nelder-Mead algorithm. Results indicate that at our study site, the turbulence intensity decreases from the lowest wind speeds $\left(0-1 \mathrm{~m} \cdot \mathrm{s}^{-1}\right)$ to reach a threshold value between 7 and $12 \mathrm{~m} \cdot \mathrm{s}^{-1}$ depending on the time of year. It then increases to reach values of the order of 0.65 . The model proposed in this study performs well whatever the time of the year. The Root Mean Square Error (RMSE) and the Mean Absolute Error (MAE) vary from $(0.018 ; 0.015)$ in December to $(0.13 ; 0.108)$ in March. Finally, the comparative study between the new model and the Normal Turbulence Model (NTM) of the IEC (International Electrotechnical Commission) standard revealed that only the model proposed is suitable for the site of Cotonou with the lowest estimation errors $(0.03 ; 0.05)$. This model can therefore be used for the design of new wind turbines along the Benin coast in Cotonou.
\end{abstract}

\section{INTRODUCTION}

The turbulence intensity is an important parameter for the design of wind turbines as well as for the estimation of the output power of these turbines. During their operation, they may be exposed to complex meteorological conditions due to wind turbulence, the latter of which causes different loads on the blades such as fatigue and static (Cheung et al., 2016 ; Peña et al., 2015 ; Dimitrov et al., 2017 ; Kim et al., 2015). To better understand the behavior of such a turbulent system, wind fluctuation models are very important for the design and operation ofwind turbines (Leu et al., 2014). Thus, the IEC (International Electrotechnical Commission) standard (IEC 61400) developed by European and US countries is a set of design requirements to ensure the proper operation and lifetime of wind turbines. This standard therefore provides the wind turbine designer with a normal turbulence model (NTM) serving as a reference for calculating the induced load on wind turbines. These loads, which are then evaluated from this model, are used in the wind tunnel to test the resistance of blades before their use on site.
However, hypotheses about the weather conditions to which the wind turbines will be exposed are formulated in this model during the design phase. After evaluating it in some turbulent environments, several authors came to the conclusion that these assumptions do not always include all the design models and wind dynamics associated with these types of sites (Wang et al., 2013; Ren et al., 2018; Lopez-Villalobos et al., 2018). Its use can therefore lead to structural damage to the technologies installed in these areas, thus resulting in an underproduction of energy.

In our study area which is suitable for wind energy exploitation according to Donnou et al., 2019a, the work of Houngninou et al., 2017a revealed high fluctuations in surface winds. The correct turbulence intensity modeling is therefore essential for estimating the fatigue load during the design of wind turbines (Wang et al., 2013). To do this, the model proposed by Cheung et al., 2016 was used in combination with the formulations of the average wind shear profile proposed by Panofsky, 1973 and reported by Peña et al., 2008. We then modified the parameters of the model thus obtained in order to propose a new model for the Cotonou site. A numerical simulation allowed us to determine the adjustment 
constants of the new model. Finally, a comparison between the proposed model and the model of the IEC standard was made.

\section{MATERIAL AND METHODS}

\section{II.1. Material}

a- Study site

Our study site is located in the coastal area of Benin in the Gulf of Guinea. It is $125 \mathrm{~km}$ in length. This zone is between $6^{\circ} 10^{\prime}$ and $6^{\circ} 40^{\prime} \mathrm{N}, 1^{\circ} 40^{\prime}$ and $2^{\circ} 45^{\prime} \mathrm{E}$ (Figure 1).

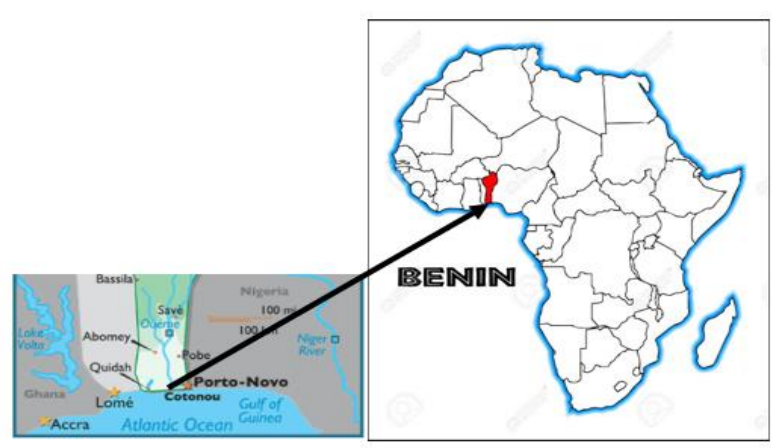

Figure 1.Geographic location of Benin's coastal zone on the map of Africa.

\section{b- Data}

The wind speed and direction data measured during the first MCA (Millennium Challenge Account) compact were used in this study. These raw data were recorded every $10 \mathrm{~min}$ at $10 \mathrm{~m}$ above the ground during the period from June 1st, 2011 to April 30th, 2014. Figure 2 shows the experimental site of Cotonou Port where measurements are performed at the seaside.

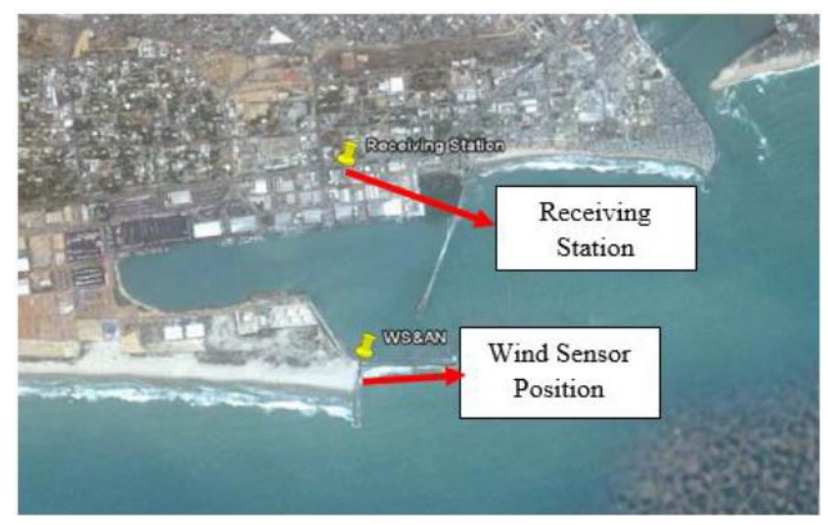

Figure 2.: Experimental site of Cotonou Port (Richard and Dolle, 2011)

\section{II.2. Theory}

a- Wind Turbulence intensity

The wind turbulence intensity is the index of wind turbulence at low frequencies. It is the ratio of the wind standard deviation to the average horizontal wind speed (Mirhosseini et al., 2011):

$$
I_{U}=\frac{\sigma}{U}
$$

$\sigma$ is the wind standard deviation $\left(\mathrm{m}^{-\mathrm{s}^{-1}}\right)$ and $\mathrm{U}$ is the horizontal wind speed $\left(\mathrm{m} \cdot \mathrm{s}^{-1}\right)$.

\section{c- IEC standards}

For the design of small wind turbines, the IEC standard 61400-2 was used to estimate the wind turbulence intensity. It expresses the 50th and 90th percentile (IEC 61400.2-2013):

$$
\begin{gathered}
I_{90}=\frac{I_{r e f}\left[\left(15 m \cdot s^{-1}+a U\right)+0.56(a+1)\right]}{(a+1) U} \\
I_{50}=\frac{I_{r e f}\left[\left(15 m \cdot s^{-1}+a U\right)-2(a+1)\right]}{(a+1) U}
\end{gathered}
$$

$I_{\text {ref }}$ equal to 0.18 represents the characteristic value of turbulence intensity at awing speed of $15 \mathrm{~m} . \mathrm{s}^{-1}$, a is the slope parameter, the values 0.56 and -2 correspond to the characteristic coefficient of the standard deviation variation.

\section{d- Turbulence intensity modeling}

In a study carried out by Cheung et al., 2016 on the modeling of the wind turbulence intensity, a simple model for estimating the turbulence intensity $I_{U}$ was proposed:

$$
I_{U}=I_{0}+\frac{\sigma}{U}
$$

$I_{0}$ is an adjustment constant. The standard deviation is given by:

$$
\sigma=\sigma_{0}+\tau_{0} l_{M B}\left(\frac{\partial U}{\partial Z}\right)
$$

$\sigma_{0}$ and $\tau_{0}$ are the adjustment constants, $l_{M B}$ is the scale length in the middle part of the atmosphere $(\mathrm{m}), \frac{\partial U}{\partial Z}$ is the average wind shear profile. In the case of our study where the data are measured at $10 \mathrm{~m}$ above the ground, $l_{M B}$ is equal to $l_{S L}$ (scale length in the surface layer). According to Peña et al., 2008, this length is a function of altitude $\left(l_{S L}=z\right.$ ). Equation (4) then becomes:

$$
I_{U}=I_{0}+\frac{\sigma_{0}+\tau_{0} z\left(\frac{\partial U}{\partial Z}\right)}{U}
$$


According to the studies of Panofsky, 1973 and reported by Peña et al., 2008, the average wind shear profile is given by:

$$
\frac{\partial U}{\partial Z}=\frac{u_{*}}{\kappa l_{S L}} \phi_{m}
$$

$u_{*}$ is the wind friction velocity $\left(\mathrm{m} \cdot \mathrm{s}^{-1}\right), \boldsymbol{\kappa}$ is the vonKarman constant $(\approx 0.40), \phi_{m}$ is the correction function of the atmospheric stability. By integrating equation (7) into equation (6) we have:

$$
I_{U}=I_{0}+\frac{\sigma_{0}+\frac{\tau_{0} u_{*}}{\kappa} \phi_{m}}{U}
$$

where the expression of $\phi_{m}$ is given for each atmospheric stability class:

- For an unstable atmosphere :

$$
\phi_{m}=\left(1+\frac{\mu z}{L}\right)^{v}
$$

- For a neutral atmosphere :

$$
\phi_{m}=1
$$

- For a stable atmosphere :

$$
\phi_{m}=1+\frac{\mu z}{L}
$$

$\mu, \nu$ are adjustment constants. $L$ is the Obukhov length (m) which characterizes the state of the atmospheric stability. The friction velocity $\boldsymbol{u}_{*}$ and the Obukhov length were determined for the Cotonou site by Donnou et al., 2019a and used in this study. By modifying the parameters of equation (8), we included the wind speed in the first term of this equation by multiplying it by $I_{0}$. We thus obtain a new model for estimating the wind turbulence intensity:

$$
I_{U}=I_{0} U^{\beta_{1}}+\left(\sigma_{0}+\frac{\tau_{0} u_{*}}{\kappa} \phi_{m}\right) U^{-\beta_{2}}
$$

$\beta_{1}$ and $\beta_{2}$ are adjustment constants. The different adjustment constants found in the models of equation (12) were determined by an optimal approach using the Nelder-Mead algorithm (Lagarias et al., 2018). This algorithm is modeled by the fminsearch function under Matlab.

\section{RESULTS AND DISCUSSION}

\section{III.1. Adjustment of the analytical model to the data}

In Figures 3 and 4, the modified model for estimating the wind turbulence intensity has been simulated for stable and unstable atmospheric conditions. These stability conditions at the study site are indicated in the study by Donnou et al., 2019a. The different adjustment constants obtained after simulation are presented in Table 1. The Root Mean Square Error (RMSE) and the Mean Absolute Error (MAE) are two indicators, which have been used in this study to evaluate the estimation errors between the proposed model and the wind turbulence intensity data. When the RSME and MAE values are close to zero, the model is better and can suitably generate the data again.

In Figures 3 and 4, we notice that during the year, except the months of August, July, September, December, the wind turbulence intensity is not a decreasing function of the wind speed. Indeed, it varies from the low wind speeds $\left(0-1 \mathrm{~m} \cdot \mathrm{s}^{-1}\right)$, with a value of the order of 3.2 for the month of March (unstable atmospheric class), to the threshold speeds between 7 and $12 \mathrm{~m} . \mathrm{s}^{-1}$ depending on the period of the year. Beyond these threshold values, the turbulence increases to reach other maxima of the order of 0.65 observed during the months of March, May, October and November. These high values would be due to the thermal turbulence, surface roughness and wind shear, as mentioned in the studies of Wang et al., 2013 and Turk and Emeis, 2010. The values recorded above 0.20 are at the origin of several structural malfunctions that could be observed on wind turbine blades, reducing their lifetime and also leading to an underproduction of energy according to the work of Stival et al., 2017, Siddiqui et al., 2015, Chowdhury et al., 2013, Adaramola and Krogstad, 2011, and Lubitz, 2011. These values must therefore be taken into account when designing future wind turbines to be operated on the Cotonou site. The lowest values of the wind turbulence are obtained in July and August whatever the atmospheric stability conditions and are due to the presence of the West African monsoon. Indeed, during this period, the temperatures are low, the winds are regular, and their speeds are almost constant. 

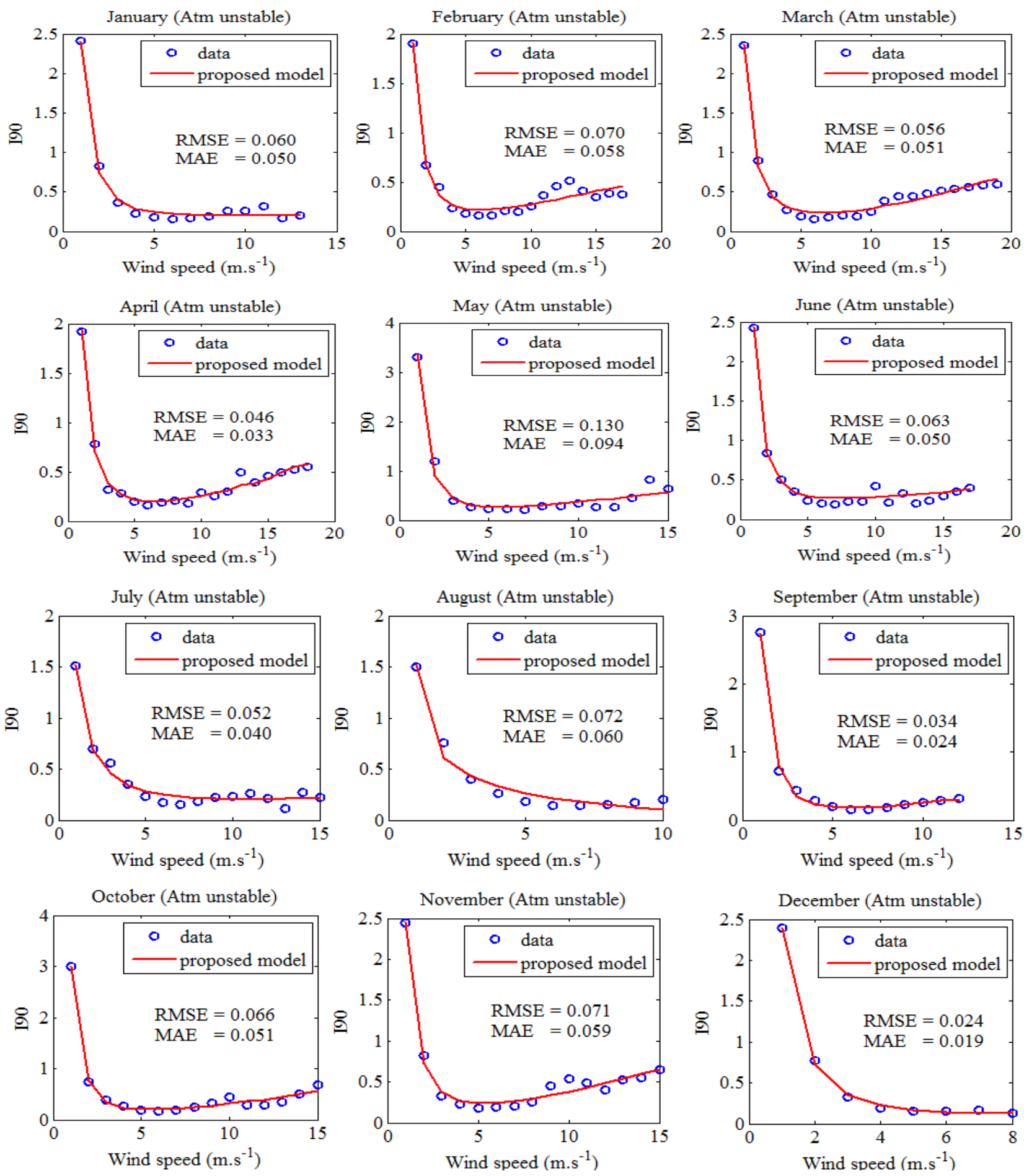

Figure 3. Evaluation of the proposed model with turbulence intensity data at $10 \mathrm{~m}$ above the ground (unstable atmosphere) 

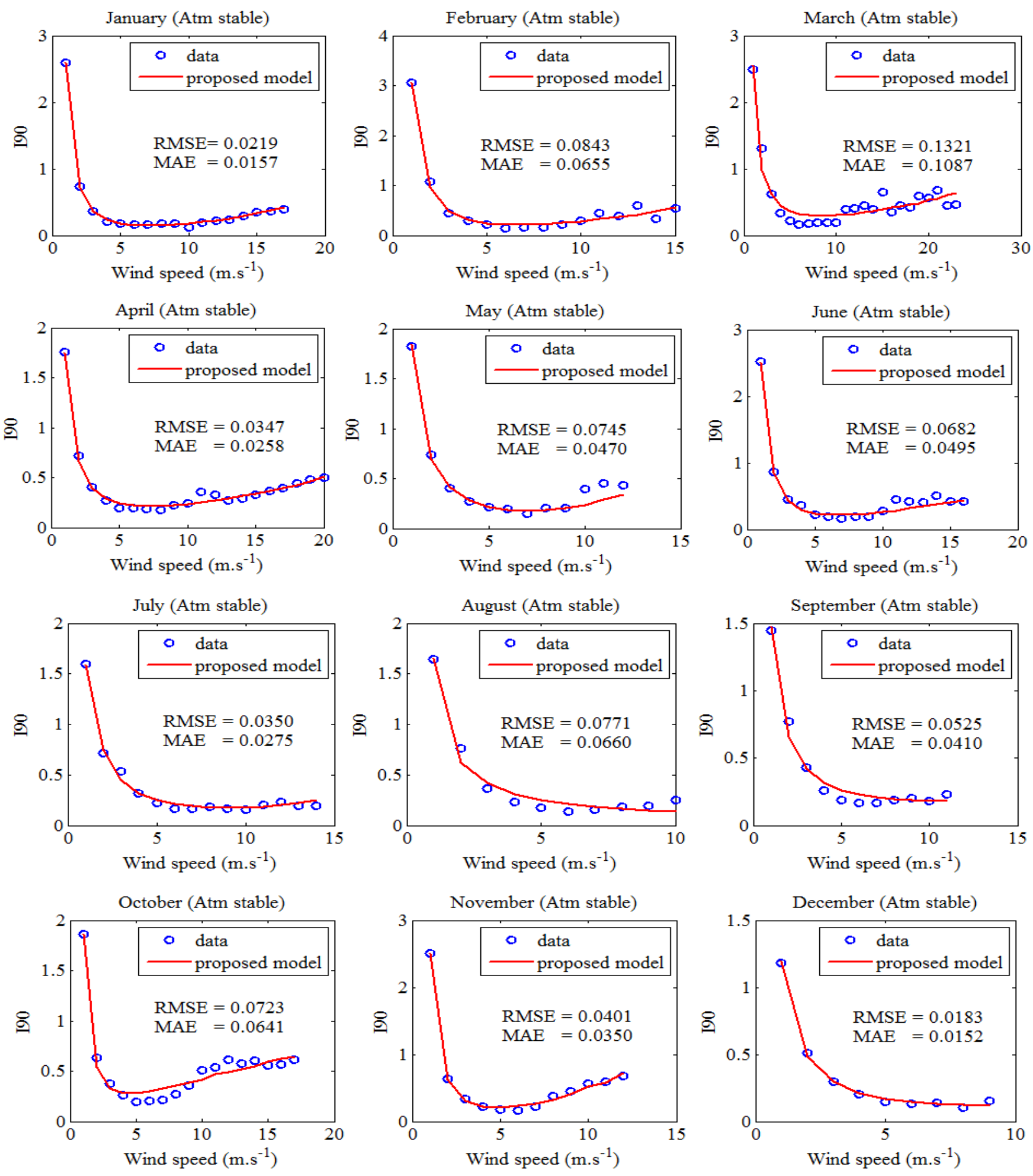

Figure 4. Evaluation of the proposed model with turbulence intensity data at $10 \mathrm{~m}$ above the ground (stable atmosphere) 
Table 1. Calibration constant values of the modified turbulence intensity model

\begin{tabular}{|c|c|c|c|c|c|c|c|c|c|c|c|c|c|c|}
\hline \multirow{3}{*}{\begin{tabular}{|r|} 
Period \\
Jan \\
\end{tabular}} & \multicolumn{14}{|c|}{ Proposed model (unstable/stable classes) } \\
\hline & \multicolumn{2}{|c|}{$I_{0}$} & \multicolumn{2}{|c|}{$\beta_{1}$} & \multicolumn{2}{|c|}{$\sigma_{0}$} & \multicolumn{2}{|c|}{$\tau_{0}$} & \multicolumn{2}{|c|}{$\mu$} & \multicolumn{2}{|c|}{$v$} & \multicolumn{2}{|c|}{$\beta_{2}$} \\
\hline & 0.08 & 0.001 & $\overline{0.29}$ & 1.96 & -1.02 & -2.6 & 1 & 1.77 & -0.32 & 1.4 & 1.04 & 1 & 1.74 & 1.54 \\
\hline Feb & 0.02 & 0.002 & 1.11 & 2.02 & -0.19 & -6.1 & 0.73 & 15.1 & -0.58 & -1.9 & 0.79 & 1 & 1.60 & 1.51 \\
\hline Mar & 0.006 & 1.66 & 1.60 & -1.09 & 1.25 & 0.3 & 0.38 & -0.19 & -3.62 & 0.27 & -0.21 & 1 & 1.40 & -1.45 \\
\hline Apr & 0.004 & 0.006 & 1.70 & 1.42 & 1.34 & 1.5 & 0.16 & -1.9 & -0.28 & -1.1 & -1 & 1 & 1.44 & 1.21 \\
\hline May & 2.02 & 1.26 & -1.87 & -1.23 & 1.15 & 0.12 & -0.38 & -0.05 & -0.38 & 1.73 & 1.28 & 1 & -1.15 & -3.03 \\
\hline Jun & 1.57 & 1.68 & -1.48 & -1.56 & 0.02 & 1.71 & 0.23 & -1.04 & 0.41 & 1.5 & 0.31 & 1 & -0.79 & -1.38 \\
\hline Jul & 1.10 & 0.0002 & -0.96 & 2.6 & -0.18 & 0.92 & 0.28 & 0.91 & 0.23 & -0.16 & -0.38 & 1 & -1.37 & 1.07 \\
\hline Aug & -0.28 & 0.016 & -0.10 & -0.07 & 0.61 & 0.98 & 1.19 & -0.02 & $\begin{array}{l}-0.27 \\
\end{array}$ & -0.52 & 0.27 & 1 & 0.58 & 0.95 \\
\hline Sep & 0.007 & 1.03 & 1.5 & -0.98 & 1.62 & 0.34 & 9.92 & -0.43 & -25.1 & \begin{tabular}{|l|l|}
0.04 \\
\end{tabular} & -2.87 & 1 & 1.69 & -1.20 \\
\hline Oct & 1.77 & 1.02 & -1.89 & -1.8 & 0.15 & 0.46 & -0.06 & 0.97 & 0.76 & -1.54 & -1 & 1 & -1.47 & -0.85 \\
\hline Nov & 0.01 & 1.42 & 1.45 & -1.77 & 1.4 & -0.005 & 8.39 & 4.01 & \begin{tabular}{|c|}
-0.26 \\
\end{tabular} & -1.87 & -8.66 & 1 & 1.71 & -1.87 \\
\hline Dec & 1.65 & 0.003 & -1.71 & 1.30 & -0.05 & 0.83 & 0.65 & 0.03 & 0.43 & -1.37 & 1.48 & 1 & -1.06 & 1.19 \\
\hline Ann & 0.079 & 1.32 & 1.53 & -1.46 & 3.30 & 0.12 & -3.29 & 0.34 & -1.26 & -1.8 & -0.70 & 1 & 1.72 & -1.09 \\
\hline
\end{tabular}

We also noticed that the modified model for estimating the wind turbulence intensity which is a function of atmospheric stability conditions, the ground friction velocity (or the roughness length) and the wind speed, gives a better fit with the data. The lowest values of the error estimators (RMSE and the MAE) are recorded during the month of December $(0.024 ; 0.019)$ for the unstable class and for the stable class $(0.0183$; $0.0152)$. The highest values are observed in May (0.13; $0.094)$ for the unstable class and in March (0.1321; 0.1087 ) for the stable class. The calibration constant values that are input parameters for the proposed model vary from one month to another. This model can then be used to estimate the fatigue loads induced on wind turbine blades in southern Benin. Accordingly, new types of wind turbines can be designed from the actual model for optimizing energy production.

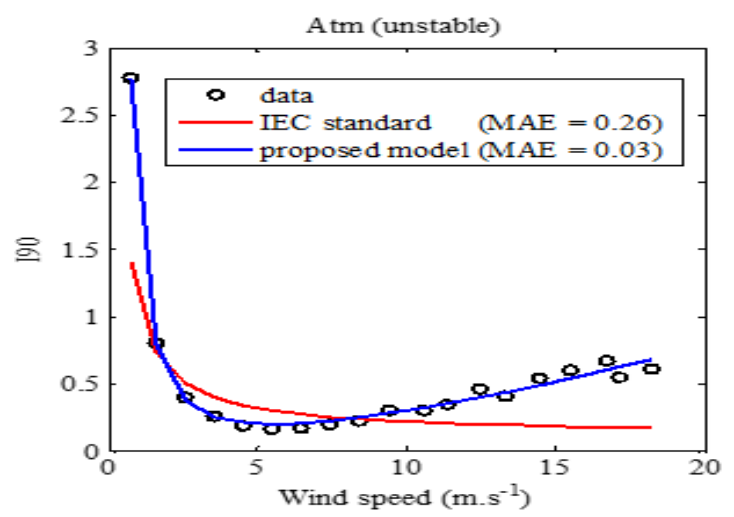

\section{III.2. Comparison between the proposed model and the model of the IEC standard.}

Figure 5 presents a comparison between the model of the IEC standard and the proposed model. It follows from this that only the model proposed is in agreement with the data whatever the period of the year with low MAE values. The model of the IEC standard has therefore demonstrated its limitations and is not suitable to the site. This result is confirmed by the studies of Ishihara et al., 2012, Wang et al., 2013, Leu et al., 2014, LopezVillalobos et al., 2018 and Ren et al., 2018 performed at others sites. The hypothesis of the wind turbulence intensity decrease over the entire range of wind speeds contained in the IEC standard is thus not verified. This turbulence distribution observed at our site is in keeping with the studies of Turk and Emeis, 2010 and Wang et al., 2013.

In table 2, we have summarized the different results obtained in this study.

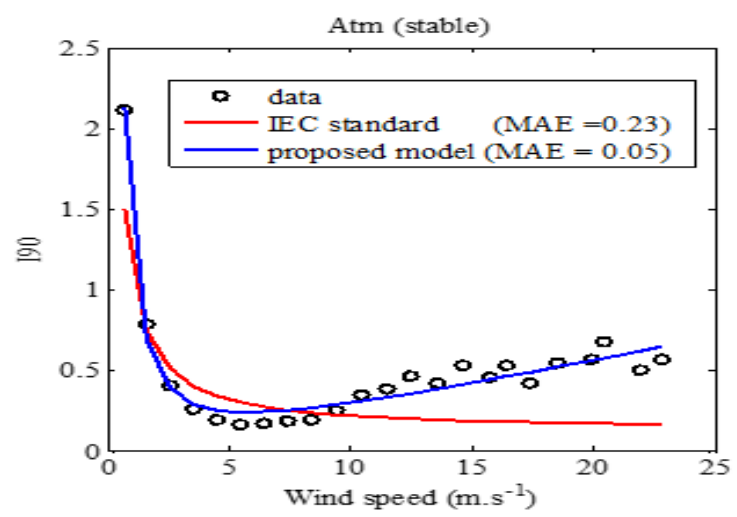

Figure 5. Comparison of the proposed model with the IEC model for small wind turbines at $10 \mathrm{~m}$ above the ground 
Table 2. Recap of the results obtained

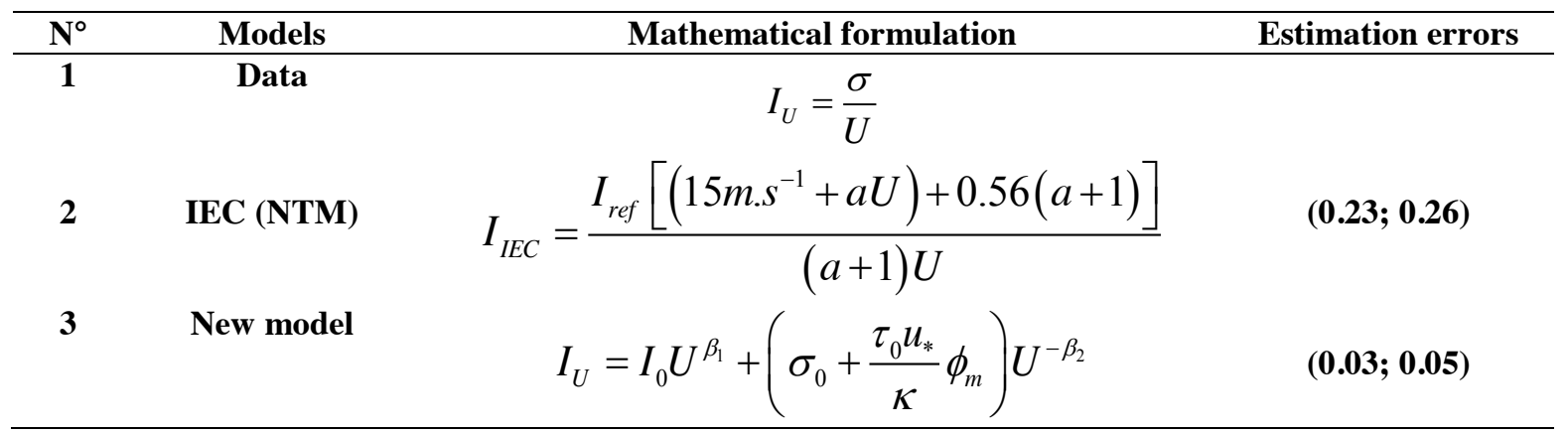

\section{Conclusion}

Wind speed and direction data were used to model the wind turbulence intensity at the Cotonou site in order to optimize energy production. From the model proposed by Cheung et al., 2016, we integrated the expression of the average wind shear profile proposed by Panofsky, 1973 and reported by Peña et al., 2008. The model obtained was then modified. The adjustment parameters in this new model were determined by numerical simulation based on the Nelder-Mead algorithm. The study shows that the turbulence intensity is not always a decreasing function of the wind speed. At our site, it decreases from the lowest wind speeds to reach a threshold value between 7 and $12 \mathrm{~m} . \mathrm{s}^{-1}$ depending on the time of year and then increases to reach values of the order of 0.65 . The proposed model is more adapted to the Cotonou site and is better than the normal turbulence model of the IEC standard with low RMSE and MAE values. It can therefore be used for the design of new wind turbines able to withstand the weather conditions along the coast of Benin.

\section{REFERENCES}

Cheung, L. C., Premasuthan, S., Davoust, S., and von Terzi, D., 2016. A Simple Model for the Turbulence Intensity Distribution in Atmospheric Boundary Layers», Journal of Physics: Conference Series 753 032008. doi:10.1088/1742-6596/753/3/032008.

Peña, A., Floors, R., Sathe, A., Gryning, S. E., Wagner, R., Courtney, M. S., Hahmann, X. G. L. A. N., and Hasager, C. B., 2015. Ten Years of Boundary-Layer and Wind-Power Meteorology at Hфvsфre. Denmark", Boundary-Layer Meteorol, Vol.158, n¹, pp. 1-26.

Dimitrov, N., Natarajan, A., and Mann, J., 2017. Effects of normal and extreme turbulence spectral parameters on wind turbine loads", Renewable Energy, Vol. 101, pp. 1180- 1193.

Kim, S. H., Shin H. K., Joo, Y. C., and Kim K.-H., 2015.A study of the wake effects on the wind characteristics and fatigue loads for the turbines in a wind farm ",Renewable Energy, Vol. 74, pp. 536-543.

Leu, T. S., Yo, J. M., Tsai, Y. T., Miau, J. J., and Wang, T. C., 2014. Assessment of IEC 61400-1 normal turbulence model for wind conditions in Taiwan West Coast areas", $5^{\text {th }}$ International Symposium on Physics of Fluids (ISPF5) International Journal of Modern Physics: ConferenceSeries34 doi:10.1142/S20101945 14603822.

Wang, H., Barthelmie, R. J., Pryor, S. C., and Kim, H. G., 2013.A new turbulence model for offshore wind turbine standards", Wind Energ, Vol. 17, $\mathrm{n}^{\circ}$ 10, pp. 1587-1604.

Ren, G., Liu, J., Wan, J., Li, F., Guo, Y. and Yu, D., 2018. The analysis of turbulence intensity based on wind speed data in onshore wind farms", Renewable Energy, doi: 10.1016/j.renene.2018.02.080.

Lopez-Villalobos, C. A., Hernandez-Cruz, O. R., Jaramillo, O. A., and Mendoza, J. L., 2018. Wind Turbulence Intensity at La Ventosa, Mexico: A Comparative Study with the IEC61400 Standards», Energies, Vol. 11, n¹1, pp. 1-19.

Donnou, H. E. V., Akpo, A. B., Kouchadé, A. C., Kounouhewa, B. B., Hounguè, G. H., Nonfodji, G. F., and Djossou, J., 2019a. Vertical profile of wind diurnal cycle in the surface boundary layer over the coast of Cotonou, Benin, under a convective atmosphere", Advances in Meteorology, Vol. 2019, pp. 1-18.

Houngninou, B. E., Allé, C. S. U., Guédjé, K. F., and Kougbéagbédè, H., 2017a. Changes in near-surface wind speed in the south of Benin from 1961 to 2016", Int. J. Adv. Res, Vol. 5, n¹1, pp. 1223-1232.

Panofsky, H. A., 1973. Tower micrometeorogy. In: Haugeb DA (ed) Workshop on micrometeorolgy", American Meteorology Society, pp. 151-176.

Peña, A., Gryning, S.-E., Charlotte, B., and Hasager, B., 2008.Measurements and Modelling of the Wind Speed Profile in the Marine Atmospheric Boundary Layer", Boundary-Layer Meteorol, Vol. 129, pp. 479-495. 
Richard, E., and Dolle, A. 2011. Data Report (MCA): Development of a metocean station at the port of 579 cotonou: Supply, installation, operation and maintenance of an oceanographic monitoring: (lot5)", 580 pp8-atm - 145c, 65p.

Mirhosseini, M., Sharifi, F., and Sedaghat, A., 2011. Assessing the wind energy potential locations in province of Semnan in Iran", Renew Sustain Energy Rev Vol. 15, pp. 449-59.

IEC 61400.2-2013. Wind Turbines Part 2. Design Requirements for Small Wind Turbines (Australia Standard: Australia",

Lagarias, J. C., Reeds, J. A., Wright, M. H., and Wright, P. E., 1998. Convergence Properties of the NelderMead Simplex Method in Low Dimensions", SIAM Journal of Optimization, Vol. 9, n 1, pp. 112-147.

Turk, M., and Emeis, S., 2010. The dependence of offshore turbulence intensity on wind speed", J. Wind Eng. Ind. Aerodyn, Vol. 98, pp. 466-471.

Stival, L. J. L., Guetter, A. K., and de Andrade, F. O., 2017. The impact of wind shear and turbulence intensity on wind turbine power performance", Espaço Energia, Vol. 27, pp. 11-20.

Siddiqui, M. S., Rasheed, A., Kvamsdal, T. K., and Tabib, M., 2015. Effect of Turbulence Intensity on the Performance of an Offshore Vertical Axis Wind Turbine", Energy Procedia, Vol. 80, pp. 312-320.

Chowdhury, S., Zhang, J., Messac, A., and Castillo, L., 2013. Optimizing the arrangement and the selection of turbines for wind farms subject to varying wind conditions", Renewable Energy, Vol. 52, pp. 273-282.

Adaramola, P., and Krogstad, A.., 2011. Experimental investigation of wake effects on wind turbine Performance", Renewable Energy, 2011, Vol. 36, pp. 2078-2086.

Lubitz, W. D., 2011. Impact of ambient turbulence on performance of a small wind turbine", Wind Energy Applications (WE) World Renewable Energy Congress, Linköping, Sweden, pp. 4121-4127.

Ishihara, T., Yamaguchi, A., Oikawa, S., and Sarwar, M. W., 2012. A Study of the Normal Turbulence Model in IEC61400-1", Wind Energy, Vol. 96, pp. 142-147. 